\section{The cost of peacekeeping: Canada}

Ross Fetterly

A great deal has been written about United Nations peacekeeping operations, including basic quantitative information such as the number and location of missions and personnel and financial support supplied by member states. In contrast, almost nothing has been written on the cost of peacekeeping from the perspective of contributing states such as Canada. This article shows that Canada incurs significant costs in support of peacekeeping deployments that are neither budgeted or otherwise explicitly accounted for over and above reported costs. The actual cost of peacekeeping to Canada is much higher than is ordinarily appreciated. This is likely to be true for other states as well and may help explain why the United Nations or other international organizations such as NATO have had difficulty calling upon peacekeeping contributions from member states.

For fiscal year 2005/6,

A great deal has been written about

United Nations peacekeeping

operations. In contrast, almost nothing

has been written on the cost of peacekeeping from the perspective of contributing states such as Canada.

Canada's Department of National Defence received C $\$ 14.3$ billion to carry out its assigned tasks, ${ }^{1}$ namely to "defend Canada and Canadian interests and values, while contributing to international peace and security."2 The top priority is the defense of Canada, followed by the defense of North America. The third priority is to contribute to international peace and security. Within that category, international peacekeeping and peace support operations are among the primary tasks and now account for a substantial portion of Canadian military activity each fiscal year. ${ }^{3}$ While homeland security remains the top statutory priority, expeditionary (deployed) operations drive the daily operational tempo. The cost of peacekeeping, nowhere explicitly budgeted for, is spread throughout the Canadian defense budget.

The Department of National Defence (DND) defines peacekeeping expenditure under the terms "full cost" and "incremental cost." The full cost is the cost to DND for the operation. Included in this cost are civilian and military wages, overtime, and allowances, full costs for petroleum, oils and lubricants, spares, contracted repair and overhaul as well as depreciation and attrition for all equipment involved. The incremental cost is the cost to DND which is over and above the amount that would have been spent for personnel and equipment if they had not been deployed on the task. It is derived from "Full DND Cost" by subtracting wages, equipment depreciation, attrition, and other costs that otherwise would have been spent on exercises or absorbed as part of normal activities.

It is important to appreciate that although there are peacekeeping costs, there is no peacekeeping budget. But because peacekeeping incurs costs, supplemental funding for defense budgets will have to be passed and future defense budget allocations will have to rise. For example, to field forces outside

Canada, the country incurs personnel costs within Canada such as costs to prepare for or recuperate from overseas deployment, costs to reconstitute unit equipment and other resources, and costs for personnel at National Defence Headquarters and Canadian military bases in general support of overseas deployment, all costs that otherwise would not have been incurred.

The next section briefly reports the funding of Canadian peacekeeping activities and outlines the shift toward peacekeeping operations in Canadian defense activity and expenditure since 1989. The section thereafter analyzes equipment deployed or in support of deployment overseas, especially with regard to the Canadian Air Force. The section finds that the costs that make overseas deployment possible are substantial and form a major hidden cost of peacekeeping that, in future, needs to be made explicit to properly guide defense and peace operations planning and budgeting.

\section{Funding and staffing peacekeeping}

Current Canadian defense policy is based on the 2005 International Policy Statement, the government's response to the post-9/11 environment. Directing Canadian forces to "address threats both at home and abroad," 4 peacekeeping, although indirectly affecting the defense of Canada and North America as well, is prominent as the third-ranked priority. The costs of Canadian deployed operations, including peacekeeping-related costs, are substantial, with incremental costs of C\$396 million in fiscal year 2004/5 alone, and full costs that year amounting to C\$927 million. ${ }^{5}$ The costs associated with peacekeeping are significant, yet are not explicitly captured or analyzed for their long-term impact on the defense budget. In particular, the increased use of equipment on deployed operations has an inflationary influence on subsequent requirements for spare parts, repair and overhaul, and the timing of equipment replacement programs. The cumulative effect of the high level of peacekeeping operations since 1989 will exert adverse 
pressures on the operations and maintenance and the capital budgets for the next fifteen years - in effect, for the time period of Canada's entire long-term capital program.

Uncertainty and change in the international security environment since the end of the Cold War have resulted in frequent unexpected, unplanned - and unfunded - deployments of Canadian military personnel. In practice, in-year incremental costs (extra costs within any given fiscal year) of unexpected deployments are submitted by DND to the Treasury Board through the Supplementary Estimates process. Indeed, DND is a significant annual beneficiary of the Supplementary Estimates funding process. Table 1 compares funding at the start of fiscal years 1993/4 to 2004/5 (the "main estimates") with year-end actual spending. ${ }^{6}$ Much of the increases result from Canadian participation in peacekeeping activities during the listed fiscal years.

Table 1: Department of National Defense funding, 1993/4-2004/5 (in C\$ million)

\begin{tabular}{lllll}
\cline { 1 - 2 } Fiscal year & & Main estimates & & Actual spending \\
\cline { 1 - 2 } $2004 / 5$ & & $13,287,516$ & & $13,922,518$ \\
$2003 / 4$ & & $12,255,000$ & & $13,185,615$ \\
$2002 / 3$ & & $11,834,000$ & & $12,415,337$ \\
$2001 / 2$ & & $11,390,000$ & & $12,243,537$ \\
$2000 / 1$ & & $11,199,000$ & & $11,469,965$ \\
$1999 / 0$ & & $10,304,500$ & & $11,521,681$ \\
$1998 / 9$ & & $9,382,721$ & & $10,256,532$ \\
$1997 / 8$ & & $9,916,518$ & & $10,187,255$ \\
$1996 / 7$ & & $10,555,000$ & & $10,573,272$ \\
$1995 / 6$ & & $11,080,000$ & & $11,373,806$ \\
$1994 / 5$ & & $11,545,000$ & & $11,773,710$ \\
$1993 / 4$ & & $11,970,000$ & & $12,003,079$
\end{tabular}

Source: Canadian Department of National Defence

The end of the Cold War resulted in an eruption of intra and interstate conflict and lead to a rapid proliferation of United Nations peacekeeping missions. As from 1990, Canada - a strong supporter of multilateralism and of United Nations international peace and security efforts - began an intense period of deployments of troops and equipment in support of United Nations (and NATO) peacekeeping in a number of continents. The table in the Appendix provides full and incremental cost information on Canadian peacekeeping. From a relatively stable level in 1989/90, costs increased dramatically as from 1990/1 onward, both in terms of full cost and of incremental costs. ${ }^{7}$ The sum total of the full cost of peacekeeping to DND from 1989/90 to 2004/5 was C\$12.7 billion, of which incremental costs amounted to $\mathrm{C} \$ 4.3$ billion.

Deployed operations have spanned the globe. Figure 1 shows significant annual variation in the number of deployed troops. ${ }^{8}$ Although peacekeeping in the Former Republic of Yugoslavia (FRY) has dominated deployed operations, Canada also participated in significant missions in Asia, the Middle East, the Americas, and Africa. Places that Canadians were little aware of before the 1990s became frequent destinations of Canadian peacekeepers. The closing of Canadian Forces Base (CFB) Baden-Soellingen in 1994 and CFB Lahr in 1995, both in Germany, had significant implications regarding deployment and sustainment costs as Canada no longer had a staging facility in Europe. Consequently, supply chains, e.g., for spare parts, had to originate in Canada.

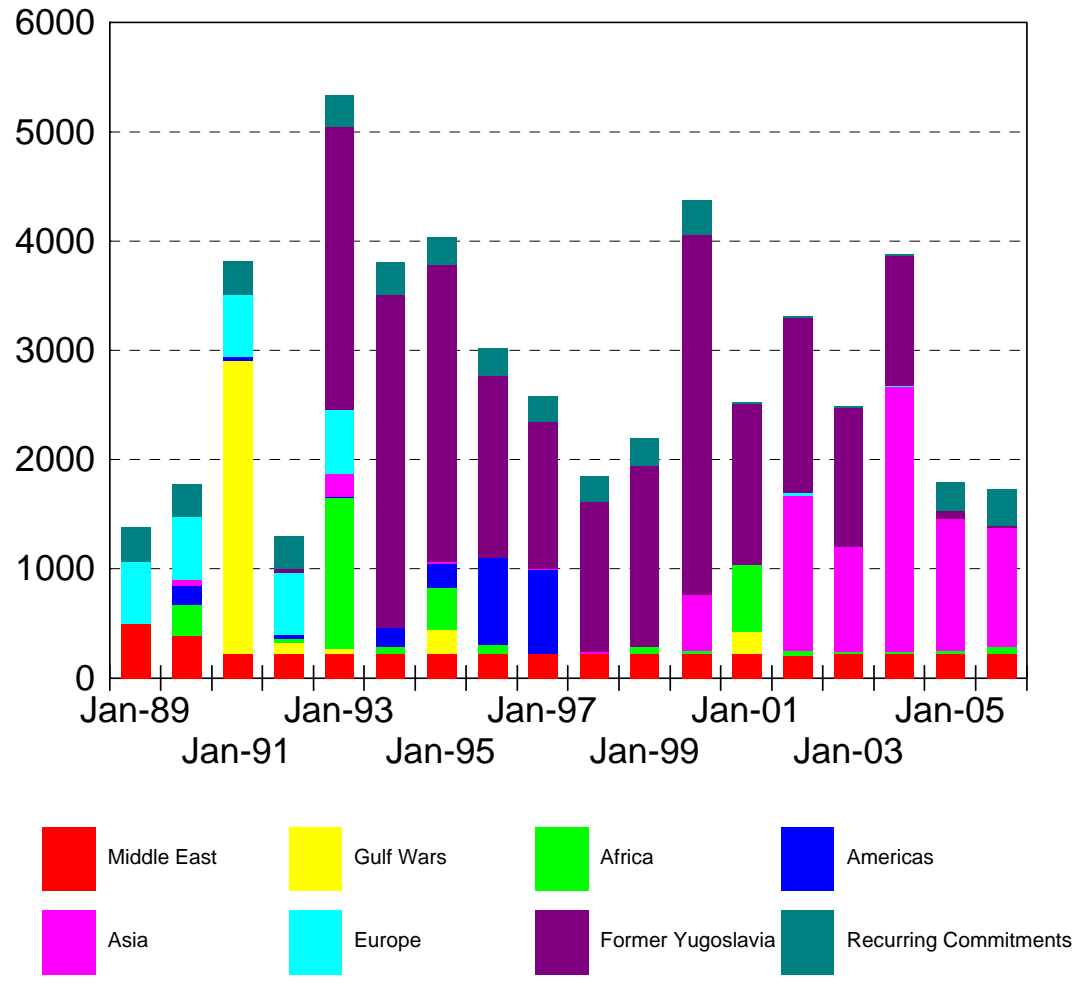

Figure 1: Personnel deployed on international operations, January 1989-2006. Source: Pollick (2006); Canadian Department of National Defence. 
In his 2002/3 annual report, the Chief of Defence Staff stated that "operations are our business and the most important and visible expression of how we make a difference and why we serve.”9 For 2002/3, in excess of 5,000 Canadian military personnel were deployed on a variety of overseas operations; their average number exceeded 2,500. Table 2 shows the cost of these deployments in terms of both full and incremental costs.

Table 2: Cost of Canadian peacekeeping deployments, fiscal year 2002/3 (in C\$ million)

\section{Europe}

SFOR Op Palladium - NATO (Bosnia)

Op Quadrant (Albania, UNMIK, UNMACC)
Op Image - NATO (DCAOC Italy)

Op Artisan - U.N. (Albania)

Subtotal - Europe

\section{Full Incremental}

$$
\begin{aligned}
& 472.9 \quad 180.7 \\
& \begin{array}{ll}
0.8 & 0.4
\end{array} \\
& 0.2 \quad 0.1 \\
& 0.1 \quad 0.1 \\
& 474.0 \quad 181.3
\end{aligned}
$$

\section{$\underline{\text { Asia }}$} Op Apollo (Afghanistan, southwest Asia)
(from Tampa, U.S.A.)

Subtotal - Asia

\section{Middle East}

Op Danaca - UNDOF (Golan Heights) $\quad 29.6 \quad 8.0$

Op Calumet - MFO (Sinai)

UNTSO - (Middle East)

Op Snowgoose - UNFICYP (Cyprus)

Subtotal - Middle East

$\begin{array}{rrr}3.0 & 0.5 \\ 1.5 & 0.7 \\ 0.3 & & 0.1 \\ 34.4 & & 9.3\end{array}$

\section{$\underline{\text { Africa }}$}

Op Addition - UNMEE (Ethopia/Eitrea)

Op Crocodile - MONUC (DRC)

Op Sculpture - IMATT (Sierra Leone)

Op Reptile - UNAMSIL (Sierra Leone)

Subtotal - Africa

Cost of all peacekeeping operations

\begin{tabular}{ll}
1.0 & 0.5 \\
1.3 & 0.3 \\
4.0 & 0.4 \\
0.6 & 0.2 \\
\cline { 2 - 2 } 6.9 & 1.4
\end{tabular}

$1,224.4 \quad 425.5$

Source: Canadian Department of National Defence
Two major peacekeeping missions determined the majority of peacekeeping costs in 2002/3. The first involved the "war on terrorism" in southwest Asia and resulted in C $\$ 234$ million in incremental costs to DND. The second was the longstanding NATO mission in Bosnia and resulted in incremental costs of C\$181 million. The third-largest Canadian peacekeeping mission in 2002/3 was substantially smaller in size, scope, and cost. This was the Canadian contribution to the United Nations mission on the Golan Heights (in which Canada has participated since 1974), and carried incremental cost to DND of C\$8 million. Canadian Forces had a further 10 missions in 2002/3. Although each incurred less than $\mathrm{C} \$ 1$ million in incremental costs, the time and effort required by National Defence Headquarters Joint Staff to manage the small numbers of peacekeepers in those missions and to monitor and adjust to changing circumstances in the respective theaters of operation was substantial.

\section{Cost of Canadian Air Force peacekeeping deployments}

Figure 2 illustrates the deployment frequency of major types of equipment used by Canadian armed forces personnel from 1990 to 2001. In particular, it demonstrates the high usage of transport aircraft fleets on foreign deployments (Boeing/Airbus, Hercules). Although the figure is limited to deployments up to 2001, it is known that these equipment types continued to be used at high operational tempo and in significant quantities through 2006. For example, the changed nature of perceived global threats, and the Canadian response thereto, resulted in a significant naval presence in the Persian Gulf region during the period immediately following 11 September 2001 and in an increased use of Armored Personnel Carriers in Afghanistan, such as the Light Armored Vehicle III (LAV 3). This demand is likely to continue for at least the remainder of the 2000s. The figure only indicates use of equipment, regardless of length of use, e.g., three months or three years. Likewise, it does it reflect intensity of equipment use.

The figure reveals that the equipment fleets of the Army, Navy, and Air Force are affected at distinctly different rates of frequency and intensity of use. This is true not only across service branches but also within each branch. For example, Figure 3 illustrates air force support to peacekeeping operations from 1990 to 2004 and demonstrates the broad range of peacekeeping roles in which Canadian Air Force personnel and their equipment have participated. ${ }^{10}$ During this time, Canada has employed CF-18 fighter aircraft in combat, its crews have operated NATO Airborne Warning and Control Aircraft (AWACS) and also CC-130 Hercules and CC-150 Polaris aircraft in a variety of transport functions. In addition, CH-146 Griffon helicopters were flown in an assortment of Army support roles, and CH124 Sea Kings and CP-140 Auroras were deployed in a number of maritime aviation operations. 


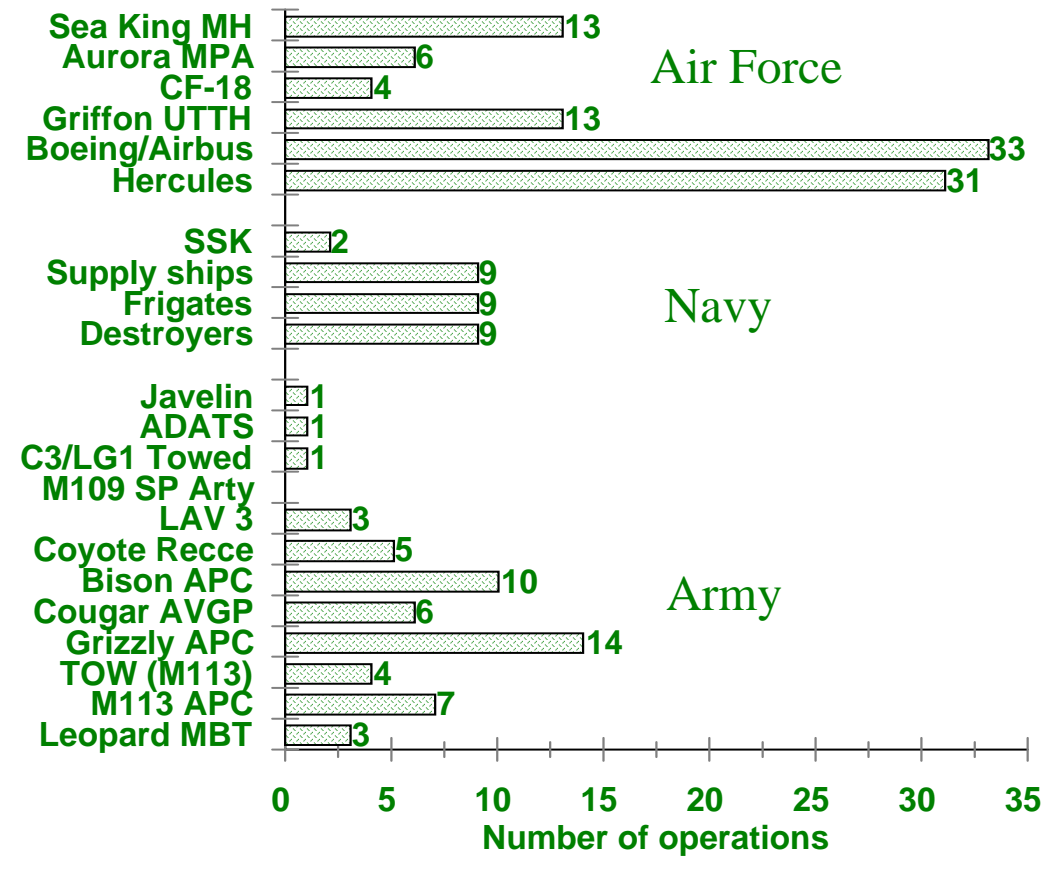

Figure 2: Fleet deployment frequency, 1990-2001, of 72 peacekeeping operations with Canadian involvement

Source: Canadian Department of National Defence

The air platforms Canada deployed in international operations from 1990 to 2004 cover virtually its entire fleet, from long-range patrol aircraft to fighters and helicopters. But in over half of the cases, strategic or tactical airlift is Canada's single-most used air asset. Maritime and tactical Army helicopter deployments occur with some frequency (generally as an organic element of Naval and Army deployments), although tactical helicopters have on occasion deployed as a standalone package. Fighter and long-range patrol aircraft tend to deploy less frequently as they are generally used in offensive or interdiction roles which occur less often than humanitarian and peacekeeping operations. In addition, Canadian Air Force aircraft often operate at long distance from their domestic Canadian Forces bases to overseas theaters of operation. In the case of airlift support, this posses a particular challenge to aircrew and maintenance personnel.

Funding for military forces is based on a combination of the tasks they are

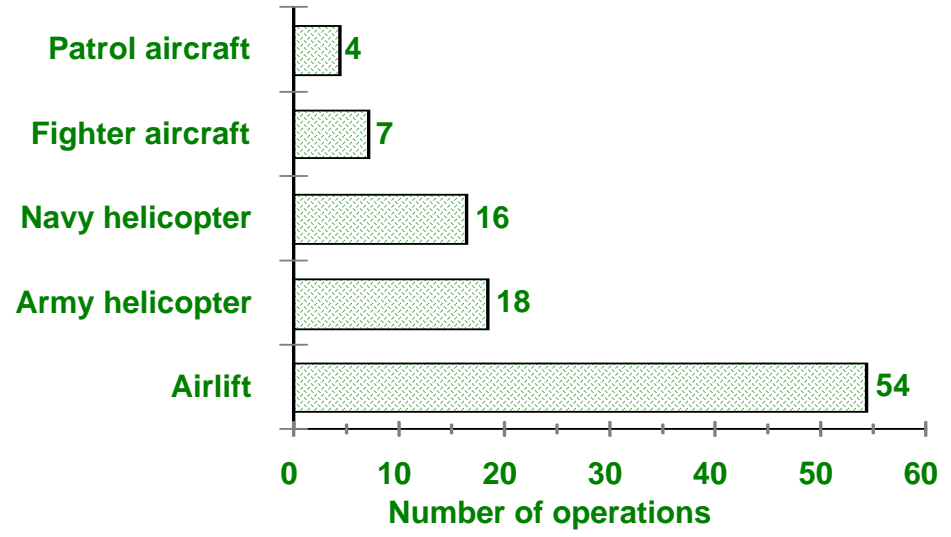

Figure 3: Canadian international contingency air operations by aircraft type, 1990-2004

Source: Canadian Department of National Defence

asked to perform and the level of activity at which they operate. The basic building block for funding is the Yearly Flying Rate (YFR) for aircraft fleets. Flying hours are the "unit" of activity. But not all flying hours on a specific type of aircraft are equal, nor do they cost the same. For example, the cost to fly CH-146 Griffon 430 Squadron helicopters from the Canadian Forces Base Valcartier in northern Quebec is less than the cost of flying the same helicopters on a peacekeeping mission in Haiti.

\section{Routine and contingency operations}

Canadian Forces operations are classified, depending on mission objectives, as either "routine" or "contingency." Routine operations are those for which a given Force Generator - the Army, Navy, or Air Force - has been specifically tasked, organized, and equipped. Existing command and control relations are used, and there is no requirement to use joint terminology. Doctrine for routine operations is generally environmental in nature, such as routine North American Aerospace Defense Command operations. If an operation does not fall into the routine category, then it is deemed to be a contingency operation, and a Task Force tailored to that operation is generated. Contingency operations can be conducted in either a domestic or an international theater.

In practice, application of the routine and contingency operation definitions within National Defence Headquarters has meant for instance that the Standing 
Naval Force Atlantic commitment - the deployment, sustainment, and redeployment of all contingency operations - as well as all North American Aerospace Defense Command operations are considered “routine.” Until 11 September 2001, these operations did not receive operation names and were not tracked in detail, and the Air Force could not point to continuous operations as an indication of operational tempo. This despite the fact that many of these "routine" operations were flown in high-risk theaters operationally identical to those of forces deployed on formal "contingency" operations. The routine nature of deployed operations is especially true of airlift, but to an extent also of maritime helicopter and maritime patrol operations. A specific air transport squadron may undertake numerous "routine" airlift operations to several different deployed operations, yet their efforts would not be reflected in the monthly statistics of deployed personnel. This high "routine" tempo, attributable to what ought to be counted as "contingency” operations, then manifests itself in budgetary follow-on costs down the road, i.e., incremental costs not previously anticipated.

Airlift support to deployed operations

Each type of aircraft in the Canadian Forces inventory was purchased to be used in specific roles and to perform certain functions. In some cases, air assets are employed to support specific naval or land operations. In other cases, aircraft, especially transport aircraft, function in a strategic role that benefits an overall mission. In effect, all Canadian in-theater forces are the recipient of these transport services. Consequently, there is no single in-theater authority to whom they are responsible. Conversely, the CH-124 Sea King and CH-146 Griffon helicopters work directly for a specific Naval or Army commander, respectively. When the commander sets operational priorities and directs front-line commanding officers, the Commanding Officer of, say, the Griffon helicopter squadron is at the table and can provide direct advice to the Army commander. But in the case of general airlift functions, decisions on theater movement priorities are made at National Defense Headquarters in the J4 Movement Organization. This can cause decision-making incentives to be skewed, with subsequent accounting and budgetary problems.

Air Transport squadrons are funded for Temporary Duty (TD) costs, based on the squadron Yearly Flying Rate. When J4 Movement tasks either 437 Squadron aircraft (CC-150) or 436 Squadron aircraft (CC-130) in Canadian Forces Base Trenton to provide airlift flights to a peacekeeping mission within the Yearly Flying Rate, costs are absorbed by the squadron. While they are direct costs to DND, they are not directly reported as deployed operations costs. When J4 Movement contracts for commercial lift in support of peacekeeping operations, the cost is funded from the departmental deployed operations peacekeeping budget. In both cases, J4 Movement must assess which alternative is the most cost effective.
The conundrum is that the closer the service provider is to the client, the better able the service provider is able to understand and manage costs. In the case of employment of Sea King and Griffon helicopters in peacekeeping operations, the client/service arrangement is predicated on immediacy.

\section{Air asset maintenance}

The high frequency of Canadian Forces aircraft deployed on operations outside Canada was shown in Figure 2. The figure does not reflect the age of the aircraft fleets. For example, many of the CC-130 Hercules pilots are younger than their aircraft, and the management of these aircraft is a significant concern. The CH-124 Sea King helicopters are the oldest fleet of aircraft in service. Purchased between 1963 and 1969, they are to be replaced by the Sikorsky H92 helicopter. Given the age of the $\mathrm{CH}-124$ Sea King helicopters and the important role they play in support of the Navy, it is worth considering how the Canadian Forces maintains the aircraft in service. Prior to operational deployments, the CH-124 Sea Kings are put through a detailed maintenance schedule. Due to the in-depth experience maintenance crews have acquired over the years with these aircraft, the Canadian Forces Supply System is able to predict with reasonable accuracy the spare parts that will be required on deployment. Any additional, unanticipated spare parts requirements are shipped to the next port that the naval vessel the helicopter is assigned to will visit. The aircraft are effectively maintained, but their age adds a significant expense.

Aircraft maintenance is either preventative or corrective. The age of the $\mathrm{CH}-$ 124 Sea Kings has necessitated an increased preventative maintenance schedule to keep the corrective maintenance at a manageable level. Corrective maintenance on old aircraft has its own unique challenges. For example, a number of spare parts are no longer available from the manufacturer or from suppliers and must be manufactured on an as-required basis. This can be very costly. Deployment of $\mathrm{CH}-$ 124 Sea Kings overseas also carries a number of associated effects, as is the case for other equipment fleets as well. For instance, maintenance on and spare part demand for aircraft about to be deployed is prioritized over aircraft remaining in Canada. One effect is that availability of aircraft remaining in Canada may decline as a result and this, in turn, adversely affects training schedules, planned domestic operations, and maintenance schedules.

Air power provides commanders with flexibility, responsiveness, and mobility, and the demand for their employment in future peacekeeping operations will likely increase. Future use of air power also will likely involve significant growth in surveillance and reconnaissance. This could involve upgraded CP-140 Auroras, CH-146 Griffons, and Unmanned Aerial Vehicles (UAVs). The air transport fleet can be expected to continue operating at a high operational tempo. Even upgraded CF-18 fighter aircraft could see action in coalition air combat operations. But aging 
aircraft require more personnel hours to maintain, and spare part costs escalate. The long service of the $\mathrm{CH}-124$ Sea Kings demonstrates that aircraft technicians can keep the aircraft airworthy, but only at steadily rising cost to the National Defence Headquarters National Procurement Budget, a cost not traditionally counted under the "peacekeeping" rubric.

\section{Conclusion}

Canadians broadly support the use of the country's armed forces in global peacekeeping missions as a distinctly Canadian contribution to international peace and security, and it is expected that peacekeeping will continue to constitute a significant activity for Canada into the next decade. But the sustained high operational tempo of Canadian peacekeeping comes with substantial hidden budgetary effects. Greater understanding of the full measure of this cost is required to assist defense planners and government decision-makers, both in Canada as elsewhere.

\section{Notes}

Lt. Col. Ross Fetterly is Director, Strategic Finance and Costing 2, Department of National Defence, Canada, and can be reached at fetterly.er@forces.gc.ca. He thanks Sean Pollick for the use of a database of deployed Canadian Forces personnel and Lt. Col. Scott Clancy for comments and advice on the Air Force case study. The views expressed here are the author's and do not necessarily reflect those of the Department of National Defence or the Canadian Forces.

1. DF (2005). On 2 March 2006, exchange rates were C $\$ 1.13 / \mathrm{US} \$ 1.00$ and C $\$ 1.36 / € 1.00$.

\section{DND (2005a).}

3. Peacekeeping is defined in a generic sense and includes peacekeeping, peacemaking, and peace support operations.

\section{DND (2005b).}

5. DND (2005c).

6. For a description of the peacekeeping cost estimate process, see Fetterly (2005).

7. DND (2005c).

8. Pollick (2006).

9. Henault (2003).
10. This section employs information and data from a presentation made to the Canadian Forces College, 2004 Air Symposium, on 9 March 2004. The presentation was written by Lt. Col. Scott Clancy, Maj. Brad Coates, Lt. Col. Ross Fetterly, Lt. Col. Robert Emond, Maj. Chantal Cloutier, Maj. Francois Laboissonniere, Maj. Hélène Couture, and Maj. Carl Doyon.

\section{References}

[DF] Department of Finance (2005). The Budget Plan 2005. Ottawa: Department of Finance Canada http://www.fin.gc.ca/budtoce/2005/budliste.htm [accessed 28 April 2006]

[DND] Department of National Defence (2005a). National Defence 2005-06. Estimates. Part III Report on Plans and Priorities. Ottawa: Public Works and Government Services. http://www.vcds.forces.gc.ca/dgsp/pubs/rep-pub/ddm/rpp/rpp_e.asp [accessed 28 April 2006]

[DND] Department of National Defence (2005b). Canada's International Policy Statement: A Role of Pride and Influence in the World (Defence Chapter). Ottawa: Department of National Defence. http://www.forces.gc.ca/site/reports/

dps/main/toc_e.asp [accessed 28 April 2006]

[DND] Department of National Defence (2005c). Total Cost of Canadian Forces Deployments 198990 to 2004-05. Ottawa: Canadian Expeditionary Force Command (J8 Financial Coordination Centre).

Fetterly, Ross (2005). "The Canadian Defence Peacekeeping Cost Estimation Process.” Resource Management (1 $1^{\text {st }}$ Quarter), pp. 28-32. Washington, DC: U.S. Army, Assistant Secretary of the Army for Financial Management and Comptroller. http://www.asafm.army.mil/proponency/rmmag/fy2005/1stQ.pdf [accessed 28 April 2006]

Henault, R. (2003). Annual Report of the Chief of Defence Staff, 2002-2003. Ottawa: Department of National Defence. http://www.cds.forces.gc.ca/pubs/ anrpt2003/intro e.asp [accessed 28 April 2006]

Pollick, S. (2006). Personnel Deployed in Operations. Spreadsheet, 1980 - 2006. Ottawa: Department of National Defence. 


\section{Appendix}

Full and incremental cost of Canadian peacekeeping deployments, 1989/90-2004/5 (in C\$ million)

\begin{tabular}{|c|c|c|c|c|c|c|c|c|c|c|}
\hline \multirow[b]{2}{*}{ Fiscal year } & \multicolumn{2}{|l|}{ Europe } & \multicolumn{2}{|l|}{ Asia } & \multicolumn{2}{|c|}{ Middle East } & \multicolumn{2}{|l|}{ Africa } & \multicolumn{2}{|c|}{ Americas } \\
\hline & $\underline{\text { Full }}$ & Incr. & Full & $\underline{\text { Incr. }}$ & $\underline{\text { Full }}$ & $\underline{\text { Incr. }}$ & $\underline{\text { Full }}$ & Incr. & $\underline{\text { Full }}$ & Incr. \\
\hline 1989-90 & & & & & 43.9 & 13.1 & 28.2 & 9.5 & & \\
\hline 1990-91 & & & 0.4 & 0.1 & 46.8 & 14.3 & 0.6 & 0.6 & 20.8 & 6.4 \\
\hline 1991-92 & 6.1 & 1.0 & 5.5 & 3.1 & 754.2 & 152.4 & 3.3 & 1.3 & 4.5 & 1.2 \\
\hline 1992-93 & 288.0 & 101.0 & 23.1 & 4.0 & 92.8 & 25.0 & 236.9 & 124.5 & 2.8 & 0.9 \\
\hline 1993-94 & 517.0 & 166.0 & 16.0 & 7.0 & 48.0 & 11.0 & 81.0 & 44.0 & 36.0 & 3.0 \\
\hline 1994-95 & 529.0 & 143.0 & 2.0 & 1.0 & 30.0 & 7.0 & 123.0 & 53.0 & 54.0 & 7.0 \\
\hline 1995-96 & 519.0 & 176.0 & 2.0 & 0.0 & 56.0 & 9.0 & 26.0 & 13.0 & 94.0 & 20.0 \\
\hline 1996-97 & 252.6 & 76.2 & 1.4 & 0.4 & 46.8 & 8.4 & 41.1 & 15.1 & 153.0 & 47.0 \\
\hline 1997-98 & 290.2 & 92.7 & 1.0 & 0.3 & 88.9 & 12.8 & & & 101.9 & 32.5 \\
\hline 1998-99 & 501.7 & 119.7 & 1.0 & 0.3 & 83.7 & 12.8 & 16.7 & 2.8 & 36.4 & 13.3 \\
\hline 1999-00 & $1,189.8$ & 340.0 & 126.9 & 33.1 & 77.5 & 12.0 & 21.4 & 3.2 & 2.5 & 1.9 \\
\hline 2000-01 & 759.2 & 220.0 & 2.8 & 2.0 & 99.9 & 15.7 & 62.5 & 28.5 & 0.2 & 0.1 \\
\hline 2001-02 & 472.6 & 169.7 & 589.6 & 190.8 & 74.0 & 12.7 & 44.8 & 18.8 & & \\
\hline 2002-03 & 474.0 & 181.3 & 709.1 & 233.6 & 34.4 & 9.3 & 6.9 & 1.4 & & \\
\hline 2003-04 & 473.1 & 180.8 & $1,167.4$ & 625.9 & 34.6 & 9.5 & 10.5 & 4.7 & 19.0 & 9.0 \\
\hline 2004-05 & 164.5 & 49.4 & 640.7 & 313.9 & 28.6 & 4.0 & 6.5 & 1.2 & 86.9 & 27.8 \\
\hline Total & $6,436.8$ & $2,016.8$ & 3,288.9 & $1,415.5$ & $1,640.1$ & 329.0 & 709.4 & 321.6 & 612.0 & 70.1 \\
\hline
\end{tabular}

Source: DND (2005c).

Notes: "Full" cost is the cost to DND for the operation. Included in this cost are civilian and military wages/overtime/allowances, full costs for petroleum, oils and lubricants, spares, contracted repair and overhaul as well as depreciation and attrition for all equipment involved. "Incremental" cost is the cost to DND which is over and above the amount that would have been spent for personnel and equipment if they had not been deployed on the task. It is derived from the "full" cost by subtracting wages,

equipment depreciation, attrition, and other costs that otherwise would have been spent on exercises or absorbed as part of normal activities. 